\title{
Stunting among children under 3 years of age in Côte d'lvoire: spatial and temporal variations between 1994 and 2011
}

\author{
Emmanuel Barankanira ${ }^{1,2}$, Nicolas Molinari ${ }^{3}$, Philippe Msellati ${ }^{2,4}$, Christian Laurent $^{2}$ and \\ Kirsten A Bork ${ }^{2, *}$ \\ 'École Normale Supérieure, Département des Sciences Naturelles, Bujumbura, Burundi: ${ }^{2}$ IRD UMI 233, INSERM U \\ 1175, Université de Montpellier, Unité TransVIHMI, BP 64501, 34394 Montpellier Cedex 5, France: ${ }^{3}$ MMAG, UMR \\ 5149/Centre Hospitalier Régional Universitaire de Montpellier/Université de Montpellier, Montpellier, France: \\ ${ }^{4} \mathrm{PACCl}$, Abidjan, Côte d'Ivoire
}

Submitted 7 April 2016: Final revision received 22 February 2017: Accepted 2 March 2017: First published online 3 April 2017

\begin{abstract}
Objective: To investigate spatial heterogeneity of stunting prevalence among children in Côte d'Ivoire and examine changes in stunting between 1994 and 2011, to assess the impact of the 2002-2011 civil war that led to temporary partitioning of the country.

Design: Data from 1994, 1998 and 2011 Côte d'Ivoire Demographic and Health Surveys (DHS) were analysed using a geostatistical approach taking into account spatial autocorrelation. Stunting data were interpolated using ordinary kriging; spatial clusters with high and low stunting prevalence were identified using Kulldorff spatial scan statistics. Multilevel multivariable logistic regression was then carried out, with year of survey as the main independent variable and an interaction term for time by geographic zone (Abidjan, South, North).

Setting: Côte d'Ivoire, West Africa.

Subjects: Children aged 0-35 months included in three DHS ( $n$ 6709).

Results: Overall stunting prevalence was 30.7, 28.7 and 27.8\% in 1994, 1998 and 2011, respectively $(P=0 \cdot 32)$. Clusters with high prevalence were found in 1994 (in the West region, $P<0.001$ ) and 1998 (in the West and North-West regions, $P<0.01$ and $P=0.01$, respectively), but not in 2011. Abidjan was included in a cluster with low prevalence in all surveys $(P<0.05)$. Risk of stunting did not change between 1994 and 2011 at national level (adjusted OR; 95\% CI: 1.39; 0.72, 2.64), but decreased in the South $(0.74 ; 0.58,0.94)$ and increased from 1998 to 2011 in Abidjan (1.96; 1.06, 3.64).

Conclusions: In Côte d'Ivoire, significant changes in stunting prevalence were observed at the sub-national level between 1994 and 2011.
\end{abstract}

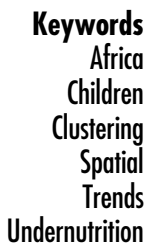

Health, nutrition, food security and care practices in developing countries are keys to development. The nutritional status of children is the most valid indicator of their well-being $^{(1)}$. Undernourished children have slow physical growth and are exposed to severe illness and premature death $^{(2)}$. Below-normal height-for-age, also called stunting, is generally considered the best indicator of undernutrition, as it measures long-term deprivation of children's basic needs. Stunting in early life is a sign of cumulative effects of individual factors: the socio-eco-political environment in which the child evolves, a low household wealth index, inadequate food intake for mother and child, maternal stunting, repeated illness and infectious diseases ${ }^{(3)}$. Reducing stunting prevalence contributes to achieve the first of the Millennium Development Goals, target $1 . C^{(4)}$, a challenging objective for sub-Saharan African countries in which $40 \%$ of the world's stunted children under 5 years of age currently reside $^{(5)}$. Reducing it by $40 \%$ in 2025 and ending it by 2030 are part of the second Sustainable Development Goal ${ }^{(6)}$.

Political instability may affect a child's well-being ${ }^{(7)}$. Civil wars and armed conflicts in several West African countries (Côte d'Ivoire, Guinea-Bissau, Sierra Leone and Liberia) have caused population displacement ${ }^{(8)}$. Côte d'Ivoire was severely affected by a civil war from 2002 to 2011, creating a demarcation line between North and South. A recent analysis of stunting from 1994 to 2011 found no change in socio-economic inequality of stunting in thirty-one out of fifty-three countries, including Côte d'Ivoire $^{(9)}$. However, a worldwide systematic analysis of nutritional changes from 1985 to 2011 reported a high 
probability of deterioration in the height-for-age $Z$-score (HAZ) of pre-school children in Côte d'Ivoire and Niger, in contrast to overall improvement in sub-Saharan Africa from the late 1990 s to $2011^{(10)}$. Conversely, a recent overview found a $4.2 \%$ decrease in the prevalence of stunting among children below the age of 2 years in Côte d'Ivoire between 1994 and 2011 ${ }^{(11)}$. The knowledge of stunting prevalence distribution at different spatial levels (country, region and zone) and its change over time may help policy decision makers to identify areas where urgent nutritional interventions are needed and to adapt national programmes and strategies to reduce the burden of stunting in Côte d'Ivoire.

The main objective of the present study was to examine stunting changes over time among children under the age of 3 years across three defined zones (i.e. Abidjan, the South and North) in Côte d'Ivoire, based on Demographic and Health Survey (DHS) and Multiple Indicator Cluster Survey (MICS) data collected in 1994, 1998 and 2011. It also sought to describe the spatial distribution of stunting across regions/zones and to detect spatial clusters of low and high stunting prevalence. Our study hypothesis was that stunting prevalence among children under 3 years of age would have increased from 1994 to 2011 in some parts of the country, and especially the North, which was economically isolated during the civil war.

\section{Methods}

\section{Study design}

The present secondary study of Côte d'Ivoire DHS data analysed changes in stunting prevalence and distribution among 0-35-month-old children in Côte d'Ivoire over a period of 17 years, using nationally representative data from Côte d'Ivoire DHS in 1994, 1998-1999 and 2011-2012.

\section{Côte d'Ivoire, the civil war 2002-2011}

During the civil war which began in September 2002, the country was divided into two parts separated by a buffer zone: a northern part, occupied by rebel forces, and a southern part, including Abidjan, controlled by the government ${ }^{(12,13)}$. The civil war led to wide-scale displacement of populations, including internal and external migrations and displacement of civil servants, teachers and health staff from the North to the South. Abidjan was the most frequent destination of these internal migrations. Conversely, some inhabitants living in the South, and especially Burkinabe citizens, fled the country.

\section{Inclusion criteria}

Our analytical sample included all children under 3 years of age who had reliable HAZ values (i.e. in the range from -6 to 6).
Design and procedures of the 1994, 1998 and 2011 Demographic and Health Surveys in Côte d'Ivoire

The 1994, 1998-1999 and 2011-2012 Côte d'Ivoire DHS were conducted by the National Statistical Institute and ORC Macro between June and November 1994, between September 1998 and March 1999, and by the National Statistical Institute and ICF Macro between December 2011 and May 2012, respectively ${ }^{(14-16)}$. All followed standardised DHS methodology and all investigators were female ${ }^{(17)}$.

The 1994 Côte d'Ivoire DHS used a stratified two-stage cluster random sample design in Abidjan and rural areas. Enumeration areas (EA, i.e. groupings of households) were selected at the first stage and households at the second stage. For other areas, a three-stage cluster design was used: cities were selected at the first stage, EA at the second stage and households at the third stage. Overall, 246 EA (146 urban and 100 rural) were selected, leading to a total of 6348 eligible households, among which 5935 (2745 urban and 3190 rural) were included (see online supplementary material, Supplemental Fig. 1). All eligible women and their children under 3 years of age were eligible for anthropometric measurements; for financial reasons, 3- and 4-year-old children were not eligible (Côte d'Ivoire DHS staff, personal communication, 16 August 2016). Weight and height information was collected for 8099 women interviewed; 3645 children under the age of 3 years were eligible.

The 1998-1999 Côte d'Ivoire DHS used a stratified two-stage cluster random sample design. Among 2302 eligible households, 2122 (1421 urban and 701 rural) were included. Weight and height were collected for 3040 interviewed women; 1221 children under 3 years of age were eligible. For the 1994 and 1998 Côte d'Ivoire DHS, the sampling frame of household groupings ( $n 246$ and $n$ 140, respectively) had been elaborated using the second General Population and Housing Census (GPHC) performed in 1987-1988 ${ }^{(18)}$.

The 2011-2012 Côte d'Ivoire DHS-MICS used a stratified two-stage cluster design. Stratification was based on eleven statistical regions and place of residence (urban or rural). The sampling frame of household groupings had been elaborated based on the third Côte d'Ivoire GPHC in 1998-1999 ${ }^{(18)}$. Among 10413 eligible households, 9686 were included. Half of the eligible households were selected for anthropometric measurements. Among 10848 eligible women, 10060 were interviewed; 2570 children under 3 years of age were eligible.

\section{Geographic data}

Côte d'Ivoire DHS collected EA geographic coordinates (latitude and longitude) using a geographic information system and global positioning system technologies. On average, urban EA grouped twenty and rural EA thirty-five households in 1994. In 1998, urban EA grouped fourteen and rural EA eighteen households, as compared with 
twenty-seven and thirty-two households, respectively, in 2011. The median household size was five inhabitants in all three surveys. Geographic coordinates were collected at the centre of the EA for all Côte d'Ivoire DHS. Geographic, household and child data sets for all three surveys are available from the DHS programme website $^{(19)}$. Geospatial data manipulations were performed using Quantum Geographic Information System software, version $1.8 .0^{(20)}$.

\section{Definition of variables}

The dependent variable was stunting, defined as a heightfor-age below -2 SD of the median height-for-age of the WHO international growth standards (i.e. $\mathrm{HAZ}<-2)^{(21)}$.
The main independent variables used were the year of survey and the zone in which the child resided. EA for the 1994 and 1998 Côte d'Ivoire DHS were allocated to the eleven statistical regions defined in the 2011-2012 DHS (Fig. 1). Next, we divided the country into three zones based on partitioning of the country during the 2002-2011 civil war ${ }^{(22)}$. These were Abidjan, the South (below the demarcation line, excluding Abidjan) and the North (above the demarcation line; Fig. 1). Other variables were sex and birth order (1, 2-3, 4-5 or $\geq 6)$, child age group (<6, 6-11, 12-17, 18-23, 24-29 and 30-35 months), education level of the mother (no formal education, primary or secondary level), BMI of the mother $(<18.5$, $18.5-25.0$ and $>25.0 \mathrm{~kg} / \mathrm{m}^{2}$, i.e. underweight, normal and (a)

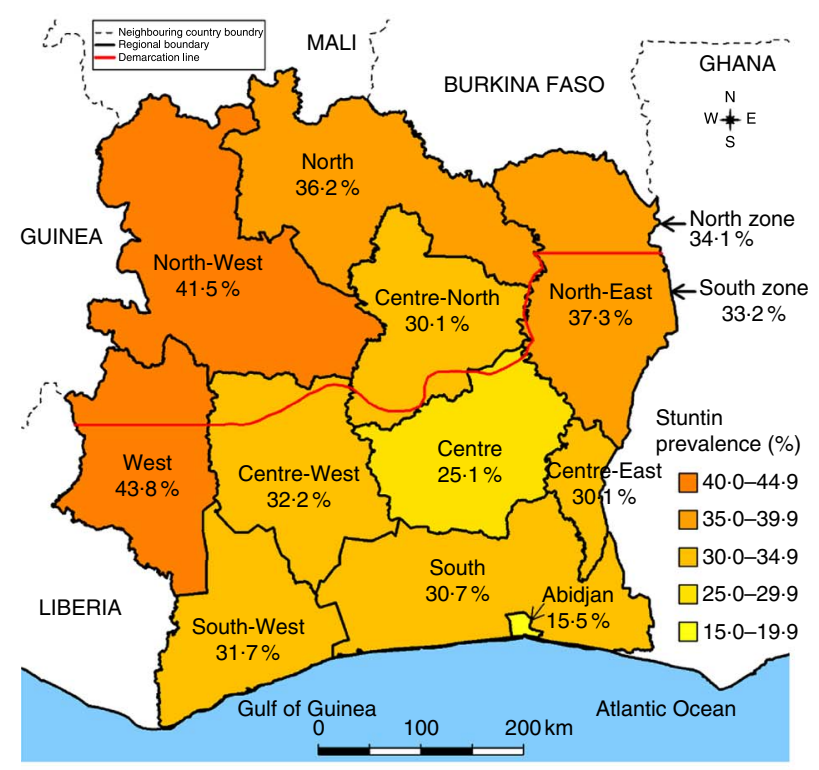

(b)

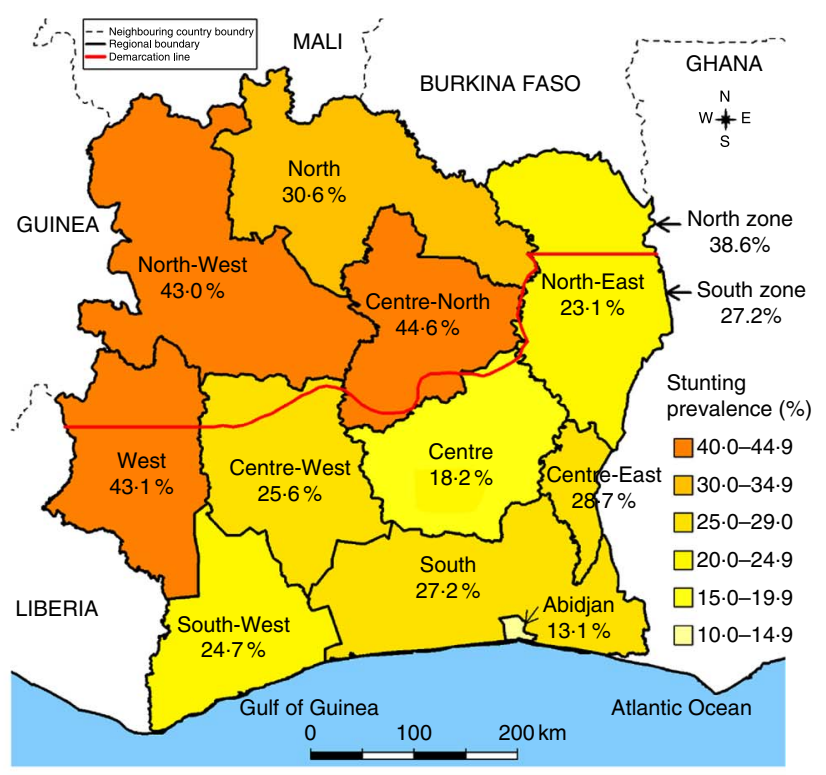

(c)

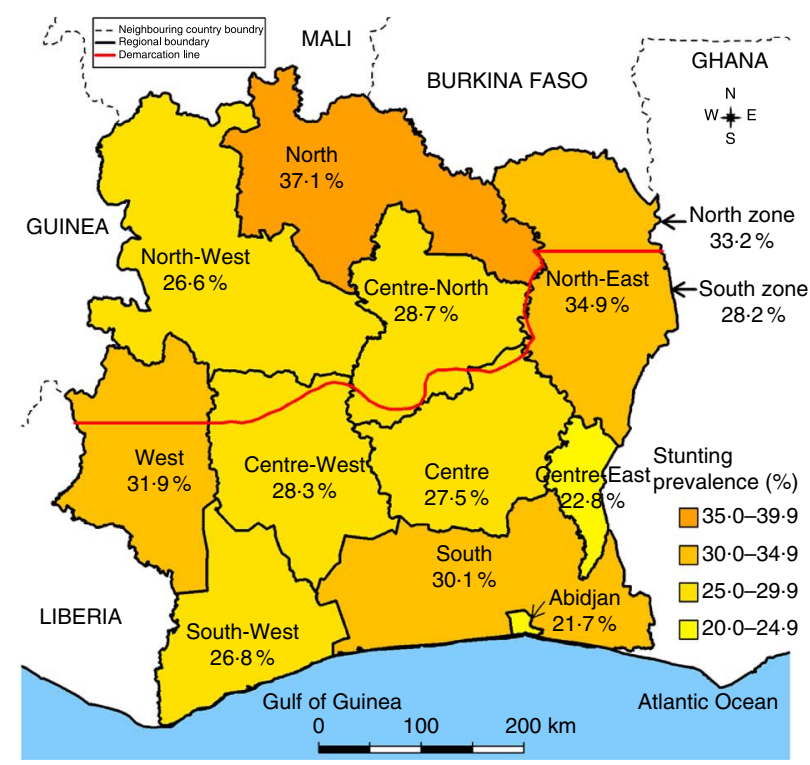

Fig. 1 (colour online) Average stunting prevalence in children aged 0-35 months in Côte d'Ivoire in (a) 1994 , (b) 1998 and (c) 2011 
overweight/obese, respectively) and economic status of the household (as defined by each Côte d'Ivoire DHS) divided into fifths.

Assets used for construction of the wealth index varied across surveys, making survey-specific indices inadequate for pooled analyses. Instead, we constructed a comparative wealth index (CWI) for each of the 1994, 1998 and 2011 Côte d'Ivoire DHS based on $\alpha$ and $\beta$ coefficients representing, respectively, the amount of adjustment and dispersion of the level of the survey-specific wealth index relative to the baseline wealth index, for 172 DHS conducted worldwide from 1990 to $2012^{(23)}$. The CWI was divided into fifths for analysis.

\section{Sampling weights}

Sampling weights, which are country- and sex-specific, are not valid for analysing pooled data ${ }^{(24)}$. For 1994 and 2011 Côte d'Ivoire DHS, we de-normalised weights using the number of females aged 15-49 years in Côte d'Ivoire in 1994 and 2011, respectively (reference: United Nations Population Division website ${ }^{(25)}$ ). For 1998, a national census was available. Thus, we used the total number of women aged 15-49 years in the 1998 Côte d'Ivoire GPHC, stratified by place of residence, and the total number of women 15-49 years old in the 1998 Côte d'Ivoire DHS database.

\section{Statistical analysis}

Stunting prevalence mapping and cluster detection

We computed the EA-based stunting prevalence for each Côte d'Ivoire DHS, globally and across the three zones (Abidjan, North and South). The overall spatial pattern of stunting prevalence was analysed using the global Moran's test. Moran's I statistics test the hypothesis that observed data at one location are independent of observed data at other locations. When this hypothesis is rejected, the use of a geostatistical approach is justified. We mapped stunting prevalence throughout the country independently of regional boundaries using the geoR library of R software, version 3.1.0 (R Core Development Team, 10 April 2014) ${ }^{(26,27)}$. We fitted the sample variograms with Matern, spherical and exponential models, respectively for 1994, 1998 and 2011 Côte d'Ivoire DHS using the VARIOFIT function. We interpolated stunting prevalence in the 1896246 points using a regular grid of $737 \mathrm{~km} \times 776 \mathrm{~km}$ and the ordinary kriging technique ${ }^{(28)}$. The kriging technique consists of predicting nearest sampled data values (EA-based stunting prevalence in our case) at unsampled spatial locations. Predicted values are weighted means of the observed values and weights are based on a variogram that measures the spatial dependence or autocorrelation between observed values. A full description of this technique can be found elsewhere ${ }^{(26-28)}$. The ordinary kriging technique, which assumes that the mean is an unknown constant over space, was chosen because it is the best linear unbiased estimator with known minimum variance $^{(29)}$.
Moreover, we used Kulldorff's spatial scan statistics (package SaTScan, version 9.3) to identify spatial clusters with high or low stunting prevalence for each Côte d'Ivoire $\mathrm{DHS}^{(30,31)}$. This method has been widely used in recent years, including in the field of child nutrition ${ }^{(32,33)}$. It enables locating areas with higher or lower numbers of stunted children than expected under the hypothesis of uniform spatial distribution of stunting. A scanning circular window of varying size gradually moves across the study area to detect areas with an excess number of stunted children. At each step, the number of observed cases in the moving window is compared with the expected number of cases assuming random spatial distribution. We used a default value of $50 \%$ of the total study population for detection of clusters and a maximum radius of $100 \mathrm{~km}$. This distance was chosen based on the results of correlogram analyses: we created a set of radiuses from 50 to $750 \mathrm{~km}$ (i.e. 50, 100, 150, etc.), covering the range of the observed distances between EA for each DHS. Each radius was used as the threshold distance for neighbourhood for all DHS in the correlogram analyses. The maximum radius beyond which the spatial autocorrelation was no longer significant was used as inputs in the spatial scan procedure. Based on Monte Carlo hypothesis testing ${ }^{(34)}$, the likelihood ratio tests and their associated $P$ values obtained through 9999 Monte Carlo replications in the Bernoulli probability model were used to ascertain the statistical significance of detected spatial clusters. The null hypothesis is that of a uniform distribution of observed number of stunted children in Côte d'Ivoire, showing equal child stunting risks across the country. When a cluster was identified, strength of clustering was ascertained using the relative risk (RR) of excess of stunted children. The estimated risk within a cluster was defined as the ratio between the observed and expected number of stunted children, and the RR was defined as the ratio between estimated risks inside the cluster $v$. outside (i.e. in the remaining part of the country). A cluster was declared significant for $P<0.05$.

\section{Temporal variations in stunting}

Assessment of trends in stunting and background variables was based on observed individual-level data recorded in the 1994, 1998 and 2011 Côte d'Ivoire DHS for the country as a whole and for each of the three zones, using a $\chi^{2}$ test for trend for the combined cross-sectional survey data. Maternal BMI was assessed for normality using the Shapiro-Wilk test and compared across surveys using the Kruskal-Wallis test. The association between stunting and background variables was assessed using $\chi^{2}$ tests.

Multilevel logistic regression models were then used ${ }^{(35)}$. The objective was to assess whether changes in stunting over time could be explained by changes in some of its major risk factors. Levels were individuals and EA. EA were used as random effects. The random effects variance-covariance structure was defined as independent. The dependent variable was stunting and the main 
explanatory variables were year of survey, zone and interaction term between year and zone. In the case of a significant interaction, the study protocol included separate logistic models for each zone. Models were adjusted for maternal education and BMI, family wealth, child's birth order, age and sex. These variables were chosen based on their association with stunting in the literature and their availability in all surveys. Cases with missing data (i.e. for birth order, maternal education or maternal BMI) were excluded. For each zone-specific model, we computed intra-cluster correlation (ICC) and median odds ratio (MOR). ICC informs us on the proportion of total variance in the outcome that is attributable to the area level ${ }^{(35,36)}$. The MOR is defined as the median value of the odds ratio of the area at higher risk compared with that at lower risk, when randomly picking out two areas. The MOR can be conceptualised as the increased risk that an individual would have (in median) if moving to another area with higher risks ${ }^{(37)}$. In our study, the MOR shows the extent to which the probability of being stunted is attributable to individual-level factors. The estimation was done using the maximum pseudo-likelihood for survey data with the svyset function ${ }^{(38)}$. The association of independent variables with risk of stunting was assessed using odds ratios and their $95 \%$ confidence intervals. The statistical software package used was Stata ${ }^{\circledR}$ release 14.

All tests were considered statistically significant for $P<0.05$.

\section{Results}

In the 1994 Côte d'Ivoire DHS, 3645 children under 3 years of age were included in the survey. We excluded 289 children $(7.9 \%)$ who had unreliable or missing height or age data, leading to 3356 children (see online supplementary material, Supplemental Fig. 1). The 1998 Côte d'Ivoire DHS included 1221 children under 3 years of age, among whom $108(8.9 \%)$ had unreliable or missing height or age data. Thus, 1113 children were kept in the analysis. In the 2011 Côte d'Ivoire DHS, there were 2570 children under 3 years of age. We excluded 330 children (12.8\%) who had unreliable or missing height or age data. Thus, 2240 children were kept in the analysis.

The study sample thus comprised 6709 children of whom 5852 had complete data for all background variables. The median number of children per EA was 10 (interquartile range (IQR) 6-19), 4 (IQR 2-11) and 5 (IQR 2-8) for Côte d'Ivoire DHS 1994, 1998 and 2011, respectively.

\section{Characteristics of the study population}

Table 1 shows the distribution of <3-year-old children by zone and other characteristics for the 1994, 1998 and 2011 Côte d'Ivoire DHS. The $\chi^{2}$ test for trend results showed that the proportion of children by zone did not change over time $(P=0 \cdot 80)$, but that the age distribution differed across
Table 1 Background characteristics of 0-35-month-old children in Côte d'Ivoire from 1994 to 2011

\begin{tabular}{|c|c|c|c|c|c|c|c|}
\hline \multirow[b]{3}{*}{ Characteristic } & \multicolumn{6}{|c|}{ Year } & \multirow[b]{3}{*}{$P^{\star}$} \\
\hline & \multicolumn{2}{|c|}{$\begin{array}{c}1994 \\
(n 3356)\end{array}$} & \multicolumn{2}{|c|}{$\begin{array}{c}1998 \\
(n 1113)\end{array}$} & \multicolumn{2}{|c|}{$\begin{array}{c}2011 \\
(n 2240)\end{array}$} & \\
\hline & $n$ & $\%$ & $n$ & $\%$ & $n$ & $\%$ & \\
\hline Zone & & & & & & & 0.803 \\
\hline Abidjan & 513 & $15 \cdot 3$ & 159 & $14 \cdot 3$ & 291 & $13 \cdot 0$ & \\
\hline South & 2117 & 63.1 & 699 & $62 \cdot 8$ & 1352 & $60 \cdot 4$ & \\
\hline North & 726 & 21.6 & 255 & $22 \cdot 9$ & 597 & $26 \cdot 6$ & \\
\hline Stunting & & & & & & & 0.318 \\
\hline Yes & 1030 & 30.7 & 309 & $27 \cdot 8$ & 644 & 28.7 & \\
\hline No & 2326 & $69 \cdot 3$ & 804 & $72 \cdot 2$ & 1596 & $71 \cdot 3$ & \\
\hline Wasting & & & & & & & 0.135 \\
\hline Yes & 366 & $10 \cdot 9$ & 94 & 8.4 & 218 & $9 \cdot 7$ & \\
\hline No & 2990 & 89.1 & 1019 & 91.6 & 2022 & $90 \cdot 3$ & \\
\hline Sex & & & & & & & 0.436 \\
\hline Male & 1704 & $50 \cdot 8$ & 551 & 49.5 & 1092 & $48 \cdot 8$ & \\
\hline Female & 1652 & $49 \cdot 2$ & 562 & $50 \cdot 5$ & 1148 & $51 \cdot 2$ & \\
\hline Age group (months) & & & & & & & 0.014 \\
\hline$<6$ & 641 & $19 \cdot 1$ & 161 & 14.5 & 362 & $16 \cdot 2$ & \\
\hline $6-11$ & 593 & $17 \cdot 7$ & 226 & $20 \cdot 3$ & 404 & $18 \cdot 0$ & \\
\hline $12-17$ & 570 & $17 \cdot 0$ & 217 & $19 \cdot 5$ & 391 & $17 \cdot 4$ & \\
\hline $18-23$ & 509 & $15 \cdot 2$ & 200 & $18 \cdot 0$ & 350 & $15 \cdot 6$ & \\
\hline $24-29$ & 551 & $16 \cdot 4$ & 166 & 14.9 & 364 & $16 \cdot 3$ & \\
\hline 30-35 & 492 & $14 \cdot 6$ & 143 & $12 \cdot 8$ & 369 & $16 \cdot 5$ & \\
\hline Birth order† & & & & & & & 0.001 \\
\hline 1 & 637 & $19 \cdot 0$ & 252 & $22 \cdot 6$ & 440 & $21 \cdot 8$ & \\
\hline $2-3$ & 1076 & $32 \cdot 1$ & 363 & $32 \cdot 6$ & 748 & $37 \cdot 0$ & \\
\hline $4-5$ & 830 & $24 \cdot 7$ & 240 & $21 \cdot 6$ & 457 & $22 \cdot 6$ & \\
\hline$\geq 6$ & 813 & $24 \cdot 2$ & 258 & 23.2 & 375 & $18 \cdot 6$ & \\
\hline Level of education $\ddagger$ & & & & & & & 0.652 \\
\hline $\begin{array}{l}\text { No formal } \\
\text { education }\end{array}$ & 2239 & $66 \cdot 7$ & 734 & $65 \cdot 9$ & 1376 & $64 \cdot 4$ & \\
\hline Primary & 826 & $24 \cdot 6$ & 298 & $26 \cdot 8$ & 562 & $26 \cdot 3$ & \\
\hline Secondary/higher & 291 & $8 \cdot 7$ & 81 & $7 \cdot 3$ & 200 & $9 \cdot 3$ & \\
\hline Mother's BMI§̧ & & & & & & & $<0.001$ \\
\hline Normal & 2371 & $77 \cdot 8$ & 766 & $76 \cdot 2$ & 1354 & $75 \cdot 1$ & \\
\hline Underweigh & 249 & $8 \cdot 2$ & 68 & $6 \cdot 8$ & 84 & $4 \cdot 7$ & \\
\hline Overweight/obese & 425 & $14 \cdot 0$ & 171 & $17 \cdot 0$ & 364 & $20 \cdot 2$ & \\
\hline CWI\| & & & & & & & 0.008 \\
\hline Poorest & 744 & $22 \cdot 2$ & 318 & 28.6 & 490 & 21.9 & \\
\hline Poorer & 685 & $20 \cdot 4$ & 270 & $24 \cdot 3$ & 522 & $23 \cdot 3$ & \\
\hline Middle & 632 & $18 \cdot 8$ & 177 & $15 \cdot 9$ & 467 & $20 \cdot 8$ & \\
\hline Richer & 575 & $17 \cdot 1$ & 143 & $12 \cdot 8$ & 491 & $21 \cdot 9$ & \\
\hline Richest & 720 & 21.5 & 205 & $18 \cdot 4$ & 270 & $12 \cdot 1$ & \\
\hline
\end{tabular}

Demographic and Health Survey sampling weights were used.

${ }^{*} P$ values of $X^{2}$ trend tests accounting for the complex sampling design. †For birth order, 220 values were missing, all in 2011.

fFor level of education, 102 values were missing, all in 2011.

$\S$ For maternal BMI, 311, 108 and 438 children had missing values in 1994, 1998 and 2011, respectively.

||The comparative wealth index (CWI) was computed based on 172 Demographic and Health Surveys conducted worldwide from 1990 to $2012^{(23)}$.

surveys $(P=0 \cdot 014)$. The distribution of birth order also changed over time $(P<0 \cdot 01)$; in particular, fewer children had a birth order $\geq 6$ in 2011 .

Two-thirds of mothers had no formal education and the level of schooling did not change between 1994 and 2011. Their median BMI was 21.6 (IQR 20.1-23.5) $\mathrm{kg} / \mathrm{m}^{2}, 21 \cdot 9$ (IQR 20.1-23.9) $\mathrm{kg} / \mathrm{m}^{2}$ and 22.2 (IQR 20.5-24.5) $\mathrm{kg} / \mathrm{m}^{2}$ in 1994, 1998 and 2011, respectively $(P<0 \cdot 001)$. The prevalence of maternal underweight decreased and that of overweight/obesity increased over time (Table 1). The CWI deteriorated in 2011; indeed, fewer children lived in the 
richest households compared with earlier years $(P<0 \cdot 01$ for differences across surveys).

The prevalence of stunting was $30 \cdot 7$ (95\% CI 28.5, 32.9) $\%, 27 \cdot 8$ (95\% CI $24 \cdot 0,31 \cdot 6) \%$ and $28 \cdot 7$ (95\% 26.2, 31.2) \% in 1994, 1998 and 2011, respectively $(P=0 \cdot 32)$. About $10 \%$ of children were wasted; this prevalence did not change between 1994 and $2011(P=0 \cdot 14)$.

\section{Spatial inequalities in stunting prevalence}

The results of Moran's tests showed that stunting prevalence data were spatially autocorrelated (Moran's $I=0 \cdot 12$ in 1994, Moran's $I=0 \cdot 19$ in 1998 and Moran's

(a)

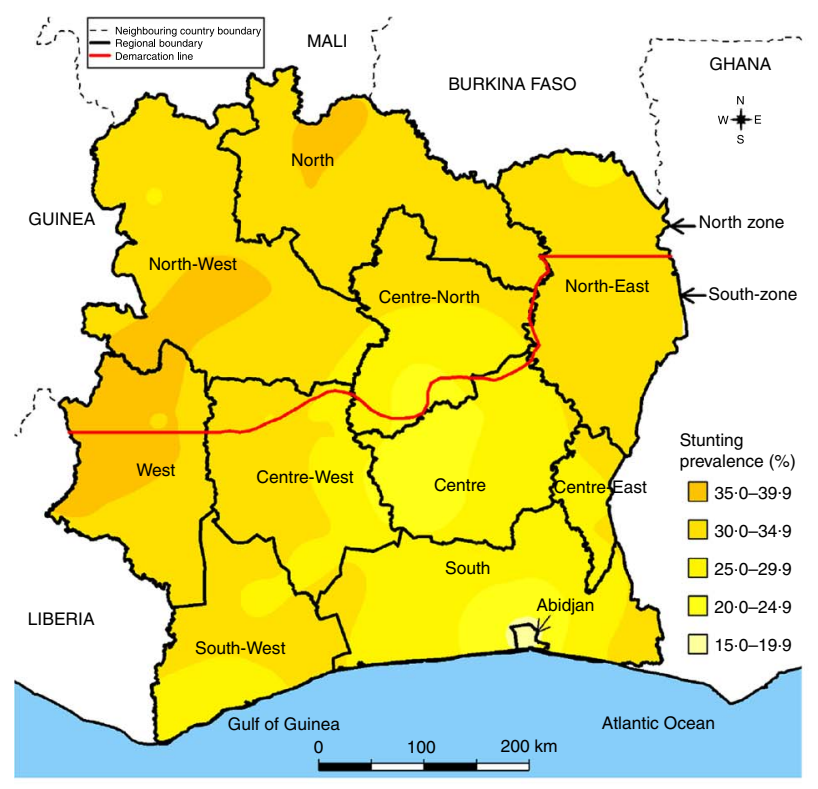

$I=0.08$ in $2011, P<0.05$ for all). Thus, the hypothesis of spatial homogeneity was rejected.

In 1994, stunting prevalence ranged between 15.5 (95\% CI $11 \cdot 8,19 \cdot 3) \%$ in Abidjan and $43 \cdot 8$ (95\% CI 37.0, 50.5) \% in the West region (Fig. 1(a)). It was close to or above $40 \%$ in the North-West, the North-East and the North regions, and was $34.1 \%$ overall in the North zone. Interpolated data showed the spatial heterogeneity of stunting independently of regional boundaries (Fig. 2(a)). The highest prevalence was observed in the North-West, West and North regions, with internal variations in prevalence in all regions and zones. Spatial scan statistics detected one significant cluster of high stunting prevalence in a radius of $79.0 \mathrm{~km}$ which ran

(b)

(c)
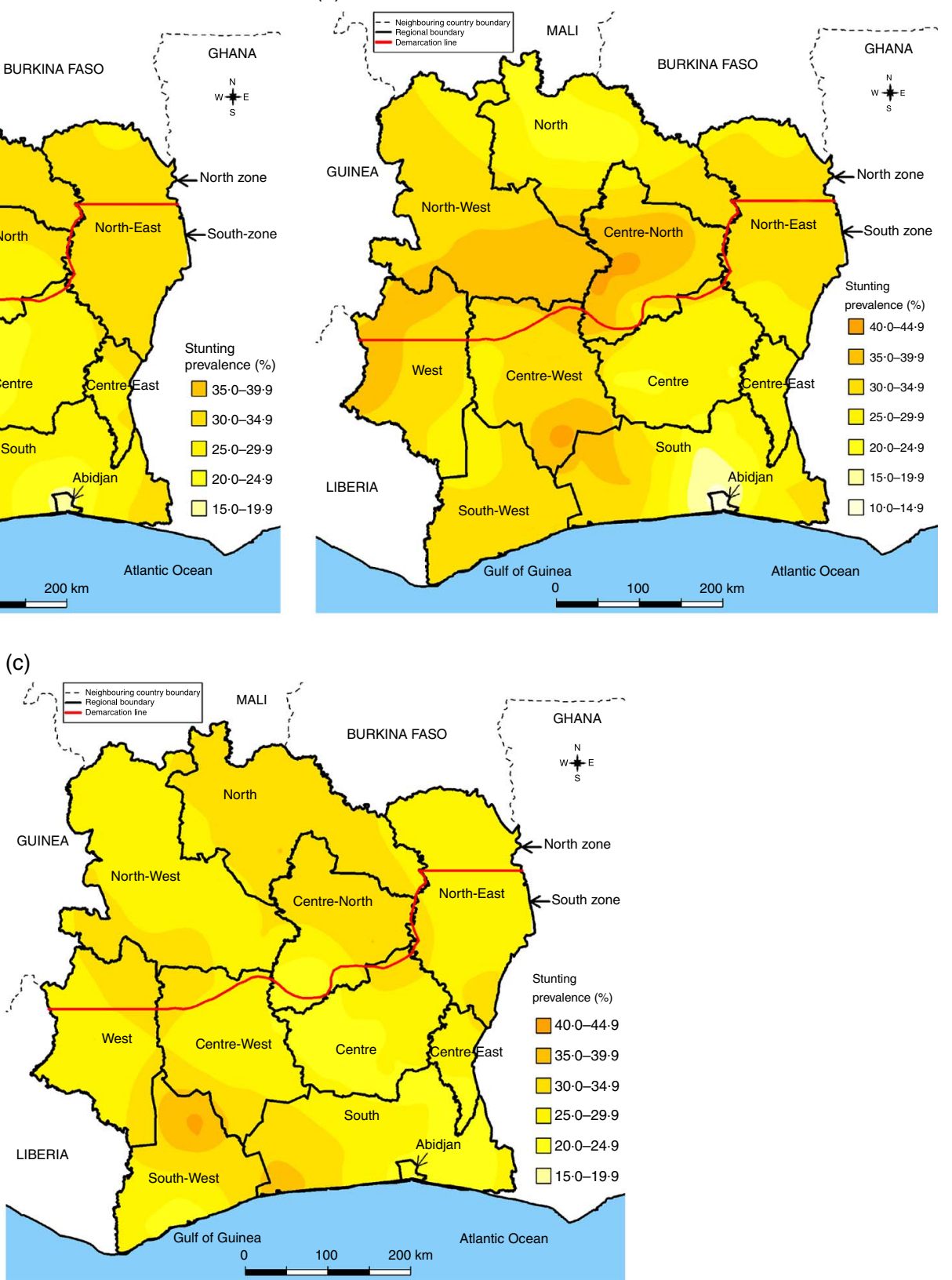

Fig. 2 (colour online) Interpolated stunting prevalence in children aged 0-35 months in Côte d'lvoire in (a) 1994, (b) 1998 and (c) 2011 
throughout the West region. This region contained eighty-six stunted children (i.e. $49 \cdot 1 \%$ of children in the cluster), giving an RR of $1.64(P<0 \cdot 001)$. Spatial scan also detected one significant cluster of low prevalence with a radius of $16.2 \mathrm{~km}$, located around Abidjan. This cluster enclosed seventy-eight stunted children (i.e. 14.5\%), giving an RR of $0.43(P<0.001$; Fig. 3(a)).

In 1998, the prevalence was high in the West, North-West and Centre-North regions, and, globally, in the North zone (Fig. 1(b)). Interpolated data showed substantial spatial heterogeneity in stunting, ranging from $10 \cdot 0$ to $44.9 \%$ across regions (Fig. 2(b)). There were areas with high risk of stunting in the Centre-West and Centre-North regions. Spatial scan statistics (Fig. 3(b)) revealed two significant clusters with high stunting prevalence, one with a radius of $94.4 \mathrm{~km}$ located in the West region $(P=0.003, \mathrm{RR}=1.93$, thirty-nine cases, i.e. $51.3 \%$ of children in the cluster) and another with a radius of $84.8 \mathrm{~km}$, centred in the North-West region $(P=0 \cdot 011, \mathrm{RR}=1 \cdot 90$, thirty-six cases, i.e. $50 \cdot 7 \%)$. There existed one significant cluster with low stunting prevalence with a radius of $17 \cdot 2 \mathrm{~km}$ located around Abidjan $(P=0.003, \mathrm{RR}=0 \cdot 48$, twenty-five cases, i.e. $14.8 \%)$.

In 2011, stunting had decreased in certain regions that had shown a high prevalence in 1994 and 1998, but not in (a)

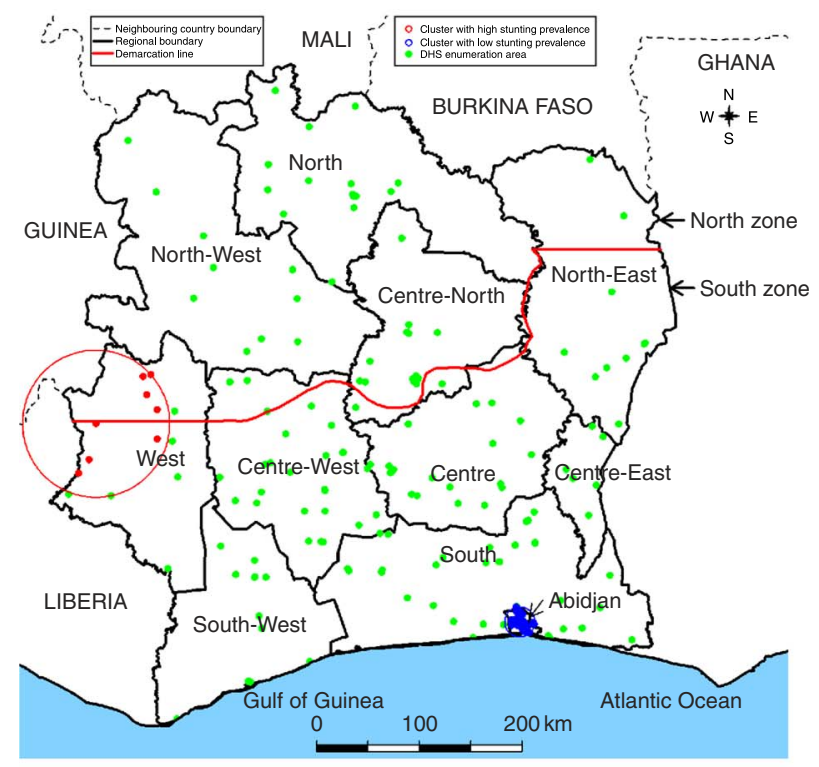

(b)

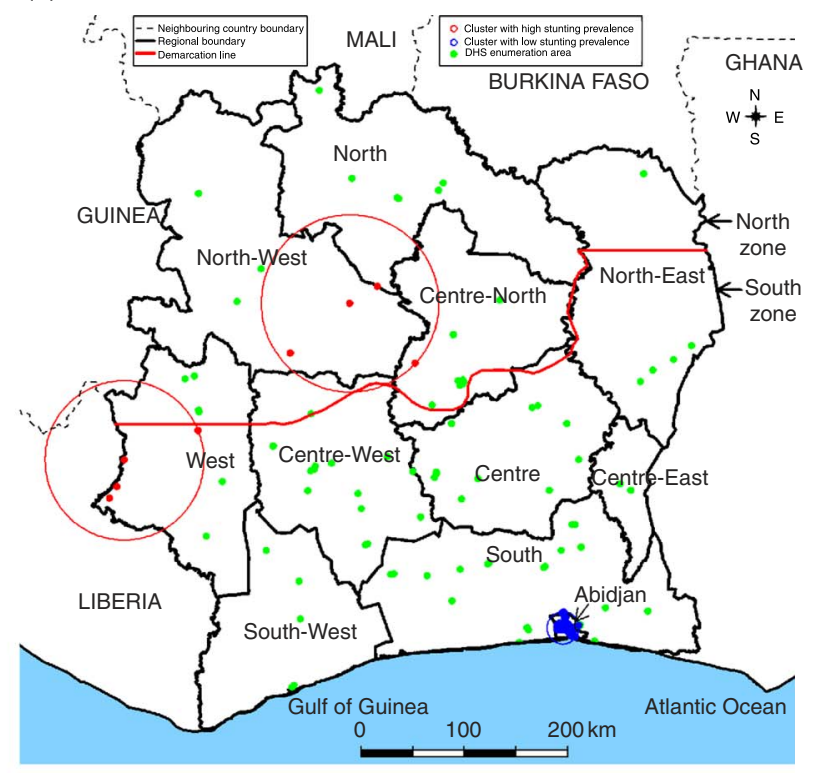

(c)

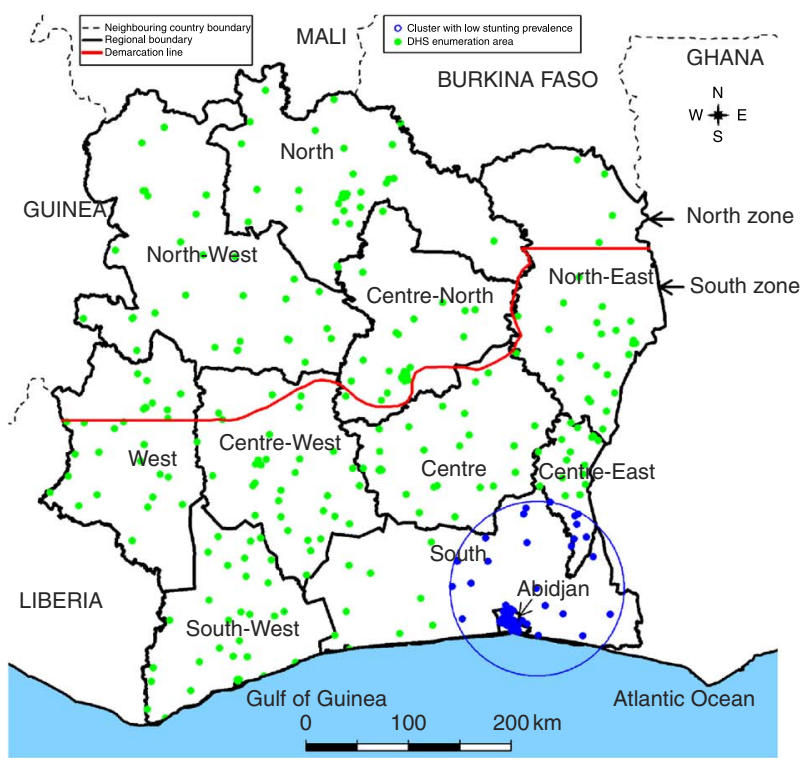

Fig. 3 (colour online) Spatial distribution of the sampling enumeration areas and clusters with high and low stunting prevalence in children aged 0-35 months in Côte d'Ivoire in (a) 1994, (b) 1998 and (c) 2011 (DHS, Demographic and Health Survey) 
the North region, where it remained high $(37 \cdot 1 \%$; Fig. 1 (c)). Interpolated data exhibited areas of high risk of stunting in the South-West, South, North and Centre-North regions (Fig. 2(c)). Spatial scan statistics showed no clusters with high prevalence, but one cluster with low prevalence and a radius of $93.7 \mathrm{~km}(P=0.010, \mathrm{RR}=0.67$, ninety-five cases, i.e. $20 \cdot 6 \%$ of children in the cluster) located under the secession line and covering Abidjan and parts of the South (Fig. 3(c)).

For all years under study, stunting prevalence was lowest in Abidjan (15.5, 13.1 and $21.7 \%$, respectively).

\section{Temporal variations in stunting}

Unadjusted logistic regression analyses based on all 6709 children showed no significant change in stunting prevalence from 1994 to 1998 or from 1994 to 2011 in Côte d'Ivoire as a whole ( $P>0 \cdot 20$; Table 2$)$. The $\chi^{2}$ test for trend results showed that there was no linear trend in stunting for Abidjan (15.5, 13.1 and $21.7 \%$ for the three surveys, respectively, $P=0 \cdot 11$ ), but the odds were significantly higher in 2011 than in $1998(\mathrm{OR}=1 \cdot 85,95 \%$ CI 1·08, 3·15). In the South, there was a significant negative trend in stunting over time $(33 \cdot 2,27 \cdot 2$ and $28 \cdot 3 \%$, respectively, for the three surveys, $P$ for trend=0.024); compared with 1994, OR of stunting in 1998 and 2011 were both significantly below 1 , i.e. 0.75 (95\% CI 0.56, 0.995) and 0.79 (95\% CI 0.66, 0.96), respectively. There was no difference across years of survey for the North.

All covariables were significantly associated with stunting, either in the whole country (sex, age, family wealth, maternal education and BMI) or in the South zone (birth order; results not shown).

Multivariable logistic regression analysis was conducted in 5852 complete cases. The proportion of excluded children was 9.2, 9.6 and 19.6\% in 1994, 1998 and 2011, respectively $(P<0.001)$, and did not differ by zone $(P=0.29)$. Excluded children were more likely to be stunted than complete cases in the South zone in 1994 (45.7 v. 31.8\%, $P<0.001)$ and 1998 (42.1 v. 25.4\%, $P=0.017)$, and in Abidjan in 1998 (33.3 v. $10.5 \%, P<0 \cdot 01)$, but not in the remaining zones and years $(P>0 \cdot 10$ for all).

In multivariable regression, a significant interaction existed between year and zone $(P=0 \cdot 028)$, with children living in the
South and surveyed in 2011 having a lower risk (Table 3). Therefore, logistic regression analyses for complete cases were performed separately for the three zones, as per protocol (sample sizes were 845, 3630 and 1377 children in Abidjan, South zone and North zone, respectively). In the South, stunting decreased significantly over time. The adjusted OR were 0.71 (95\% CI 0.53, 0.95) and 0.74 (95\% CI 0.58, 0.94) for 1998 and 2011, respectively (Table 3). There was no change in the prevalence of stunting between 1998 and 2011 (Table 4). In the North, there was no significant effect of year on stunting between 1994 and 1998, or between 1994 and 2011, in adjusted analyses ( $P>0 \cdot 20$ for both; Table 3 ). Thus, adjustment did not change the association between stunting and year of survey.

In Abidjan, the prevalence of stunting did not vary either between 1994 and 1998 or between 1994 and 2011 (Table 3), but the significant increase between 1998 and 2011 that existed in the unadjusted analyses remained very similar in the fully adjusted model (adjusted OR $=1 \cdot 96$, 95\% CI 1.06, 3.64; Table 4). Between 1994 and 2011, birth order decreased in Abidjan whereas household wealth decreased from 1994 to 1998 and then increased again $(P<0.001$ for both; see online supplementary material, Supplemental Table 1).

Final zone-based logistic models showed that ICC and MOR were respectively 2.9 (95\% CI 0.8, 9.4) \% and 1.44 (95\% CI $1.21,1.98)$ in the South zone, 1.2 (95\% CI 0.0 , $24.5) \%$ and 1.27 (95\% CI 1.05, 3.33) in the North zone and $9 \cdot 0$ (95\% CI 2.9, 25.0) \% and 1.94 (95\% CI 1.44, 3.38) in Abidjan. MOR of the empty model (i.e. without explanatory variables) was 1.72 (95\% CI 1.52, 2.03) and decreased when explanatory variables were taken into account in the South and North zones, showing a significant effect of clustering in these zones, in contrast to Abidjan.

\section{Discussion}

We examined the effect of time on stunting prevalence among children aged 0-35 months in Côte d'Ivoire, globally and within three large zones (South, North and Abidjan), using 1994, 1998 and 2011 DHS data. We identified spatial clusters with high and low stunting prevalence.

Our study hypothesis was that stunting prevalence would have increased during that period because of the

Table 2 Non-adjusted effect of time on stunting prevalence in 0-35-month-old children in Côte d'Ivoire and its three zones from 1994 to 2011

\begin{tabular}{|c|c|c|c|c|c|c|c|c|c|c|c|c|c|}
\hline & \multicolumn{3}{|c|}{ Prevalence (\%) } & \multicolumn{3}{|c|}{1998 v. 1994} & \multicolumn{3}{|c|}{2011 v. 1994} & \multicolumn{3}{|c|}{2011 v. 1998} & \multirow{2}{*}{$\frac{\text { Trends analysis }}{P \dagger}$} \\
\hline & 1994 & 1998 & 2011 & OR & $95 \% \mathrm{Cl}$ & $P^{\star}$ & OR & $95 \% \mathrm{Cl}$ & $P^{\star}$ & OR & $95 \% \mathrm{Cl}$ & $P^{\star}$ & \\
\hline \multicolumn{14}{|l|}{ Zone } \\
\hline Abidjan & $15 \cdot 5$ & $13 \cdot 1$ & $21 \cdot 7$ & 0.82 & $0.49,1.38$ & 0.455 & 1.51 & $0.88,2.61$ & 0.136 & 1.85 & $1.08,3 \cdot 15$ & 0.024 & 0.106 \\
\hline South & 33.2 & $27 \cdot 2$ & $28 \cdot 3$ & 0.75 & $0.56,1.00$ & 0.046 & 0.79 & $0.66,0.96$ & 0.017 & 1.06 & $0.78,1.45$ & 0.701 & 0.024 \\
\hline North & $34 \cdot 1$ & 38.6 & $33 \cdot 2$ & $1 \cdot 28$ & $0.90,1.81$ & 0.173 & 0.96 & $0.72,1.28$ & 0.782 & 0.75 & $0.53,1.07$ & 0.117 & 0.429 \\
\hline Côte d'Ivoire & $30 \cdot 7$ & $27 \cdot 8$ & $28 \cdot 7$ & 0.93 & $0.73,1.17$ & 0.525 & 0.91 & $0.78,1.07$ & 0.250 & 0.98 & $0.77,1.25$ & 0.889 & 0.318 \\
\hline
\end{tabular}

Data are based on de-normalised sample weights.

${ }^{*} P$ values for multilevel logistic regression.

$\dagger P$ values of $x^{2}$ tests for trend. 
Table 3 Multivariable mixed-effects logistic regression analysis of factors associated with stunting in 0-35-month-old children in Côte d'Ivoire and its three zones from 1994 to 2011

\begin{tabular}{|c|c|c|c|c|c|c|c|c|c|c|c|c|}
\hline \multirow[b]{2}{*}{ Characteristic } & \multicolumn{3}{|c|}{ Côte d'Ivoire (n 5852) } & \multicolumn{3}{|c|}{ Abidjan ( $n$ 845) } & \multicolumn{3}{|c|}{ South zone ( $n$ 3630) } & \multicolumn{3}{|c|}{ North zone $(n 1377)$} \\
\hline & $\mathrm{aOR}$ & $95 \% \mathrm{Cl}$ & $P$ & $\mathrm{aOR}$ & $95 \% \mathrm{Cl}$ & $P$ & aOR & $95 \% \mathrm{Cl}$ & $P$ & $\mathrm{aOR}$ & $95 \% \mathrm{Cl}$ & $P$ \\
\hline Year & & & 0.090 & & & 0.102 & & & 0.007 & & & 0.632 \\
\hline 1994 & 1.00 & Ref. & & 1.00 & Ref. & & 1.00 & Ref. & & 1.00 & Ref. & \\
\hline 1998 & 0.64 & $0.34,1.20$ & 0.165 & 0.82 & $0.48,1.41$ & 0.478 & 0.71 & $0.53,0.95$ & 0.020 & 1.20 & $0.81,1.79$ & 0.361 \\
\hline 2011 & 1.39 & $0.72,2.64$ & 0.323 & 1.62 & $0.87,3.01$ & 0.129 & 0.74 & $0.58,0.94$ & 0.012 & 1.00 & $0.72,1.39$ & 0.992 \\
\hline Zone & & & 0.034 & NA & & & NA & & & NA & & \\
\hline Abidjan & 1.00 & Ref. & & & & & & & & & & \\
\hline South & 1.81 & $1 \cdot 14,2 \cdot 87$ & 0.012 & & & & & & & & & \\
\hline North & 1.87 & $1.14,3.06$ & 0.012 & & & & & & & & & \\
\hline Zone $\times$ year & & & 0.028 & NA & & & NA & & & NA & & \\
\hline Abidjan + 1994 & 1.00 & Ref. & & & & & & & & & & \\
\hline South + 1998 & 1.09 & $0.55,2 \cdot 16$ & 0.811 & & & & & & & & & \\
\hline South +2011 & 0.53 & $0.27,1.05$ & 0.069 & & & & & & & & & \\
\hline North + 1998 & 1.96 & $0.94,4.12$ & 0.074 & & & & & & & & & \\
\hline North + 2011 & 0.69 & $0.33,1.41$ & 0.305 & & & & & & & & & \\
\hline Sex & & & 0.019 & & & 0.060 & & & 0.002 & & & \\
\hline Male & 1.00 & Ref. & & 1.00 & Ref. & & 1.00 & Ref. & & & & \\
\hline Female & 0.77 & $0.62,0.96$ & 0.019 & 0.66 & $0.42,1.02$ & 0.060 & 0.70 & $0.56,0.88$ & 0.002 & & & \\
\hline Age group (months) & & & $<0.001$ & & & 0.002 & & & $<0.001$ & & & 0.001 \\
\hline$<6$ & 1.00 & Ref. & & 1.00 & Ref. & & 1.00 & Ref. & & 1.00 & Ref. & \\
\hline $6-11$ & 1.03 & $0.70,1.51$ & 0.897 & 2.22 & $0.78,6.31$ & 0.134 & 0.94 & $0.57,1.54$ & 0.807 & 1.03 & $0.53,2.02$ & 0.927 \\
\hline $12-17$ & 1.80 & $1 \cdot 22,2 \cdot 64$ & 0.003 & 4.42 & $1.70,11.46$ & 0.002 & 1.67 & $1.07,2.60$ & 0.023 & 1.71 & $0.72,4.04$ & 0.222 \\
\hline $18-23$ & $2 \cdot 77$ & $1.82,4.22$ & $<0.001$ & 4.51 & $1.69,12.01$ & 0.003 & 2.89 & $1.62,5.17$ & $<0.001$ & $2 \cdot 31$ & $1 \cdot 29,4 \cdot 13$ & 0.005 \\
\hline $24-29$ & $2 \cdot 65$ & $1.78,3.96$ & $<0.001$ & 4.80 & $2.01,11.46$ & 0.001 & 2.58 & $1 \cdot 62,4 \cdot 12$ & $<0.001$ & $2 \cdot 29$ & $0.92,5.71$ & 0.075 \\
\hline $30-35$ & 3.70 & $2.48,5.52$ & $<0.001$ & 7.05 & $2.77,17.94$ & $<0.001$ & 3.70 & $2 \cdot 17,6 \cdot 30$ & $<0.001$ & $3 \cdot 18$ & $1.56,6.52$ & 0.002 \\
\hline Birth order & & & 0.467 & & & 0.003 & & & & & & \\
\hline 1 & 1.00 & Ref. & & 1.00 & Ref. & & & & & & & \\
\hline $2-3$ & 0.84 & $0.66,1.07$ & 0.156 & 1.38 & $0.80,2.37$ & 0.242 & & & & & & \\
\hline $4-5$ & 0.84 & $0.64,1 \cdot 10$ & 0.201 & 0.44 & $0.21,0.92$ & 0.029 & & & & & & \\
\hline$\geq 6$ & 0.82 & $0.60,1.13$ & 0.225 & 1.48 & $0.76,2.91$ & 0.249 & & & & & & \\
\hline Level of education & & & 0.028 & & & 0.200 & & & 0.114 & & & 0.177 \\
\hline No formal education & 1.00 & Ref. & & 1.00 & Ref. & & 1.00 & Ref. & & 1.00 & Ref. & \\
\hline Primary & 0.78 & $0.62,0.99$ & 0.037 & 0.78 & $0.43,1.39$ & 0.391 & 0.76 & $0.58,1.00$ & 0.047 & 0.97 & $0.65,1.46$ & 0.893 \\
\hline Secondary/higher & 0.68 & $0.49,0.96$ & 0.027 & 0.56 & $0.29,1.06$ & 0.072 & 0.81 & $0.51,1.28$ & 0.359 & 0.57 & $0.31,1.04$ & 0.066 \\
\hline Mother's BMI & & & 0.001 & & & & & & 0.031 & & & 0.001 \\
\hline Normal & 1.00 & Ref. & & & & & 1.00 & Ref. & & 1.00 & Ref. & \\
\hline Underweight & 1.46 & $1.04,2.05$ & 0.028 & & & & 1.11 & $0.71,1.74$ & 0.658 & $2 \cdot 20$ & $1.35,3.57$ & 0.002 \\
\hline Overweight/obese & 0.65 & $0.49,0.87$ & 0.004 & & & & 0.58 & $0.38,0.88$ & 0.010 & 0.61 & $0.37,0.99$ & 0.045 \\
\hline Wealth index & & & 0.004 & & & & & & 0.049 & & & 0.119 \\
\hline Poorest & 1.00 & Ref. & & & & & 1.00 & Ref. & & 1.00 & Ref. & \\
\hline Poorer & 0.84 & $0.62,1.13$ & 0.246 & & & & 0.90 & $0.64,1.26$ & 0.537 & 0.78 & $0.44,1.37$ & 0.388 \\
\hline Middle & 0.80 & $0.60,1.06$ & 0.113 & & & & 0.89 & $0.62,1.27$ & 0.513 & 0.70 & $0.45,1.09$ & 0.114 \\
\hline Richer & 0.80 & $0.58,1.12$ & 0.196 & & & & 0.96 & $0.62,1.48$ & 0.834 & 0.74 & $0.44,1.24$ & 0.249 \\
\hline Richest & 0.47 & $0.31,0.70$ & $<0.001$ & & & & 0.45 & $0.25,0.79$ & 0.006 & 0.41 & $0.21,0.79$ & 0.008 \\
\hline
\end{tabular}

aOR, adjusted odds ratio; Ref., reference category; NA, not applicable.

Each model includes only variables that were significant at $P<0.20$ in univariable and adjusted models.

Data are based on de-normalised sample weights.

2002-2011 civil war, especially in the North, which was economically isolated. The analysis showed that there was no overall significant change in stunting. The North showed a fairly constant prevalence and we even found a significant reduction in stunting between 1994 and 2011 in the large southern zone of the country (adjusted $\mathrm{OR}=0.74 ; 95 \%$ CI $0.58,0.94)$. Only Abidjan had an increased risk from 1998 to 2011.

The analysis also confirmed our hypothesis of the existence of substantial spatial heterogeneity in stunting across regions and zones in all three surveys. The spatial dimension of stunting is often analysed using exploratory spatial data analysis techniques at the national and regional level ${ }^{(39)}$. In addition, the analysis presented here included spatial patterns of stunting prevalence on a local scale $^{(40)}$. This was achieved using the Kulldorff spatial scan test as a local clustering test ${ }^{(41)}$.

In 1994, stunting was most prevalent in the North $(34.1 \%)$, in particular in the North and North-West regions and parts of the West and North-East regions. In spatial analyses, we identified a cluster with high prevalence in the West region (43.8\%). These results are consistent with those of a study conducted in Côte d'Ivoire in $1990^{(42)}$. In 1998, the highest stunting prevalence was found in the Centre-North, West and North-West regions, which contained two high-risk areas.

For all surveys, a cluster with low stunting prevalence was found in the South, centred on Abidjan. This was expected 
Table 4 Multivariable mixed-effects logistic regression analysis of factors associated with stunting in 0-35-month-old children in Côte d'Ivoire and its three zones from 1994 to 2011, with 1998 as the year of reference

\begin{tabular}{|c|c|c|c|c|c|c|c|c|c|c|c|c|}
\hline \multirow[b]{2}{*}{ Characteristic } & \multicolumn{3}{|c|}{ Côte d'Ivoire } & \multicolumn{3}{|c|}{ Abidjan } & \multicolumn{3}{|c|}{ South zone } & \multicolumn{3}{|c|}{ North zone } \\
\hline & $\mathrm{aOR}$ & $95 \% \mathrm{Cl}$ & $P$ & aOR & $95 \% \mathrm{Cl}$ & $P$ & aOR & $95 \% \mathrm{Cl}$ & $P$ & $\mathrm{aOR}$ & $95 \% \mathrm{Cl}$ & $P$ \\
\hline Year & & & 0.136 & & & 0.102 & & & 0.007 & & & 0.632 \\
\hline 1998 & 1.00 & Ref. & & 1.00 & Ref. & & 1.00 & Ref. & & 1.00 & Ref. & \\
\hline 1994 & $1 \cdot 18$ & $0.94,1.49$ & 0.146 & 1.21 & $0.71,2.08$ & 0.478 & 1.41 & $1.06,1.88$ & 0.020 & 0.83 & $0.56,1.24$ & 0.361 \\
\hline 2011 & 1.01 & $0.78,1.31$ & 0.936 & 1.96 & $1.06,3.64$ & 0.013 & 1.04 & $0.74,1.46$ & 0.842 & 0.83 & $0.55,1.28$ & 0.400 \\
\hline Sex & & & 0.023 & & & 0.060 & & & 0.002 & & & \\
\hline Male & 1.00 & Ref. & & 1.00 & Ref. & & 1.00 & Ref. & & & & \\
\hline Female & 0.78 & $0.63,0.97$ & 0.023 & 0.66 & $0.42,1.02$ & 0.060 & 0.70 & $0.56,0.88$ & 0.002 & & & \\
\hline Age group (months) & & & $<0.001$ & & & 0.002 & & & $<0.001$ & & & 0.001 \\
\hline$<6$ & 1.00 & Ref. & & 1.00 & Ref. & & 1.00 & Ref. & & 1.00 & Ref. & \\
\hline $6-11$ & 1.05 & $0.72,1.53$ & 0.809 & 2.22 & $0.78,6.31$ & 0.134 & 0.94 & $0.57,1.54$ & 0.807 & 1.03 & $0.53,2.02$ & 0.927 \\
\hline $12-17$ & 1.79 & $1 \cdot 22,2 \cdot 64$ & 0.003 & 4.42 & $1 \cdot 70,11.46$ & 0.002 & 1.67 & $1.08,2.60$ & 0.023 & 1.71 & $0.72,4.04$ & 0.222 \\
\hline $18-23$ & $2 \cdot 80$ & $1.85,4.25$ & $<0.001$ & 4.51 & $1.69,12.01$ & 0.003 & 2.89 & $1.62,5 \cdot 17$ & $<0.001$ & $2 \cdot 31$ & $1.29,4.13$ & 0.075 \\
\hline $24-29$ & 2.65 & $1.79,3.93$ & $<0.001$ & $4 \cdot 80$ & $2 \cdot 01,11.46$ & 0.001 & 2.58 & $1.62,4.12$ & $<0.001$ & $2 \cdot 29$ & $0.92,5.71$ & 0.144 \\
\hline $30-35$ & 3.74 & $2 \cdot 52,5.56$ & $<0.001$ & 7.05 & $2 \cdot 77,17.94$ & $<0.001$ & 3.70 & $2 \cdot 17,6 \cdot 30$ & $<0.001$ & $3 \cdot 18$ & $1.56,6.52$ & 0.002 \\
\hline Birth order & & & 0.559 & & & 0.003 & & & & & & \\
\hline 1 & 1.00 & Ref. & & 1.00 & Ref. & & & & & & & \\
\hline $2-3$ & 0.87 & $0.68,1 \cdot 10$ & 0.236 & 1.38 & $0.80,2.37$ & 0.242 & & & & & & \\
\hline $4-5$ & 0.84 & $0.64,1.09$ & 0.192 & 0.44 & $0.21,0.92$ & 0.029 & & & & & & \\
\hline$\geq 6$ & 0.84 & $0.61,1.16$ & 0.286 & 1.48 & $0.76,2.91$ & 0.249 & & & & & & \\
\hline Level of education & & & 0.007 & & & 0.200 & & & 0.114 & & & 0.177 \\
\hline No formal education & 1.00 & Ref. & & 1.00 & Ref. & & 1.00 & Ref. & & 1.00 & Ref. & \\
\hline Primary & 0.74 & $0.59,0.94$ & 0.012 & 0.78 & $0.43,1.39$ & 0.391 & 0.76 & $0.58,1.00$ & 0.047 & 0.97 & $0.65,1.46$ & 0.893 \\
\hline Secondary/higher & 0.65 & $0.46,0.90$ & 0.011 & 0.56 & $0.29,1.06$ & 0.072 & 0.81 & $0.51,1.28$ & 0.359 & 0.57 & $0.31,1.04$ & 0.066 \\
\hline Mother's BMI & & & 0.001 & & & & & & 0.031 & & & 0.001 \\
\hline Normal & 1.00 & Ref. & & & & & 1.00 & Ref. & & 1.00 & Ref. & \\
\hline Underweight & 1.49 & $1 \cdot 05,2 \cdot 13$ & 0.027 & & & & 1.11 & $0.71,1.74$ & 0.658 & $2 \cdot 20$ & $1.35,3.57$ & 0.002 \\
\hline Overweight/obese & 0.63 & $0.47,0.85$ & 0.002 & & & & 0.58 & $0.38,0.88$ & 0.010 & 0.61 & $0.37,0.99$ & 0.045 \\
\hline Wealth index & & & $<0.001$ & & & & & & 0.049 & & & 0.119 \\
\hline Poorest & 1.00 & Ref. & & & & & 1.00 & Ref. & & 1.00 & Ref. & \\
\hline Poorer & 0.77 & $0.57,1.04$ & 0.089 & & & & 0.90 & $0.64,1.26$ & 0.537 & 0.78 & $0.44,1.37$ & 0.388 \\
\hline Middle & 0.72 & $0.55,0.95$ & 0.021 & & & & 0.89 & $0.62,1 \cdot 27$ & 0.513 & 0.70 & $0.45,1.09$ & 0.114 \\
\hline Richer & 0.71 & $0.51,0.97$ & 0.033 & & & & 0.95 & $0.62,1.48$ & 0.834 & 0.74 & $0.44,1.24$ & 0.249 \\
\hline Richest & 0.38 & $0.26,0.55$ & $<0.001$ & & & & 0.45 & $0.25,0.79$ & 0.006 & 0.41 & $0.21,0.79$ & 0.008 \\
\hline
\end{tabular}

aOR, adjusted odds ratio; Ref., reference category.

Each model includes only variables that were significant at $P<0.20$ in univariable and adjusted models.

Data are based on de-normalised sample weights.

given the higher socio-economic level in the capital city. However, there was an increase in stunting between 1998 and 2011. This might be due to a massive arrival of refugees from the North during the civil war ${ }^{(43)}$ and/or to a global negative impact of the war on the nutritional situation of children below the age of 3 years.

At the time of the last survey in 2011, the civil war had just ended. The aftermath of the civil war, mainly in the North, involved theft of livestock, destruction of public infrastructures and crops, shortage of human resources, economic contraction, and displacement of health staff and populations towards the southern parts ${ }^{(44-46)}$. A recent study in Côte d'Ivoire provided evidence that children from conflict-affected regions (South-West, West, North-West, North, Abidjan, North-East regions) or households having experienced economic stress during the period 2002-2007 (measured by loss of productive assets such as jobs, farms and livestock, or a decrease in income) had lower mean HAZ than those from less conflict-affected regions ${ }^{(47)}$. Our findings are also consistent with those of a study carried out in 2014 which showed that childhood health was affected in regions around Guiglo (West region), Bouaké (Centre-North region) and Korhogo (North region), where numerous conflicts occurred $^{(44)}$.

The civil war was not the only socio-economic event during the years under study. In addition, the western part of the country, where stunting was highly prevalent in 1994 and 1998, suffered from land-related conflicts between indigenous ethnic groups and non-Ivoirians, among them Liberians, who fled the 1999-2003 Liberian civil war ${ }^{(44)}$.

In the 1990s, the purchasing power of the population decreased due to a decline in international cocoa prices ${ }^{(48)}$. Another major macroeconomic change was the 50\% devaluation of the national currency, the Communaute Financière Africaine francs (CFAF), in February $1994^{(49)}$. This change, which affected most French-speaking countries in West and Central Africa, was shown to have a negative impact on the nutritional status of pre-school children in Brazzaville, Congo, between 1993 and 1996 ${ }^{(50)}$. However, it is doubtful that a macroeconomic event in February 1994 would already have affected stunting of children below the age of 3 years at the time of the Côte d'Ivoire DHS, carried out from June to November 1994. 
Indeed, stunting is a cumulative process and environmental insults have the greatest impact on linear growth from conception to age $12-18$ months ${ }^{(51)}$. Thus, the high stunting prevalence in the West and North-West regions in 1994 was probably largely independent of the currency devaluation.

Spatial variations in pre-school stunting have been reported previously in sub-Saharan countries, for example in the Democratic Republic of the Congo, which suffered severe regional conflicts ${ }^{(52)}$. In 2007, the prevalence was very high in the eastern provinces affected by conflicts $(46 \cdot 1 \%)$, but also in those relying on mining. In Nigeria, there was a strong south-north gradient in stunting prevalence among pre-school children in 2008, ranging from $11.6 \%$ in one southern state to $59.7 \%$ in a northern state ${ }^{(39)}$.

To our knowledge, the present study is the first making use of spatial techniques to analyse the effect of time on the prevalence of stunting in Côte d'Ivoire. However, the study had limitations. One was the rather low sample size in the 1998 Côte d'Ivoire DHS, limiting the statistical power of tests. Second, multivariate logistic regression was conducted on complete cases after exclusion of $12 \cdot 8 \%$ of children with missing data (for birth order, maternal education and BMI). It was not possible to estimate missing data using multiple imputations, due to the lack of other relevant background variables in the DHS databases. In some surveys and zones (three out of nine), stunting prevalence was higher for excluded children than for complete cases. Thus, although the results of multivariate analyses were very similar to those of unadjusted analyses, we cannot exclude that the observed change in stunting over time in the South zone or Abidjan was explained by changes in background variables such as birth order, maternal BMI or economic level.

Finally, we acknowledge that the current secondary analysis of Côte d'Ivoire DHS data could not formally link sub-national trends in stunting to the civil war. Since data are cross-sectional, we were not able to distinguish 'true' changes in young child nutritional status in a given population (due to changes in feeding and/or caring practices) from changes in population composition due to massive arrival of residents to certain areas such as Abidjan.

Our findings show the progress made by Côte d'Ivoire in reducing stunting among young children at a local scale before and after the civil war. The exploration of spatial and spatiotemporal variations of stunting prevalence should provide national public health decision makers with useful information for nutritional interventions. The recent increase in stunting in Abidjan is a matter of concern, but its prevalence remained much lower than in the South and North zones. Although the North zone contributed less to the total amount of stunted children in the country than the South zone, due to its lower population density, it requires attention. Indeed, the reduction of inequalities in nutrition within the country is an important development goal.

\section{Conclusion}

In conclusion, the analysis presented here shows that the overall prevalence of stunting remained stable in Côte d'Ivoire between 1994 and 2011 despite the civil war, but that this average hides significant and contrasting changes at the sub-national level. Further analyses are needed to assess how and where the prevalence of stunting has changed in Côte d'Ivoire since the civil war ended in 2011. In the meantime, public health efforts should be reinforced throughout the country because stunting prevalence remained high in all three zones.

\section{Acknowledgements}

Acknowledgements: The authors thank the Institut National de la Statistique (INS) of Côte d'Ivoire and ICF International, which performed the 1994 and 1998-1999 Côte d'Ivoire DHS; the INS, the Ministère de la Santé et de la Lutte contre le Sida (Côte d'Ivoire) and ICF International, which performed the 2011-2012 Côte d'Ivoire DHS; and MEASURE DHS which provided the databases. They are grateful to Aurégan Xavier (Institut Français de Géopolitique, Université Paris 8), who kindly provided information on the demarcation line and buffer zone in Côte d'Ivoire, and to Françoise Gubry (UMR 196 CEPED Université Paris Descartes - Ined - IRD), who provided the 1998 Côte d'Ivoire GPHC report. Financial support: E.B. was the recipient of a doctoral fellowship from the Ministry of Education, Higher Education and Scientific Research in Burundi. Conflict of interest: None. Authorship: E.B., K.A.B., N.M., P.M. and C.L. elaborated the study design. E.B. obtained permission to use the 1994, 1998-1999 and 20112012 Côte d'Ivoire DHS data, performed statistical analysis and, with K.A.B., wrote the first draft of the paper. All authors contributed to interpretation of results, reviewed the draft and approved the final version of the manuscript. Ethics of buman subject participation: This study was conducted according to the guidelines laid down in the Declaration of Helsinki and all procedures involving human subjects were approved by the Ethics Committee of ICF International at Calverton, MD, USA and by the National Ethics Committee of Côte d'Ivoire. Written informed consent was obtained from all mothers. This secondary study analysed existing publicly available survey data. MEASURE DHS de-identified these data before our access to the databases.

\section{Supplementary material}

To view supplementary material for this article, please visit http://dx.doi.org/10.1017/S1368980017000544 


\section{References}

1. de Onis M, Frongillo EA \& Blössner M (2000) Is malnutrition declining? An analysis of changes in levels of child malnutrition since 1980. Bull World Health Organ 78, 1222-1233.

2. Prendergast AJ \& Humphrey JH (2014) The stunting syndrome in developing countries. Paediatr Int Child Health 34, 250-265.

3. Black RE, Allen LH, Bhutta ZA et al. (2008) Maternal and child undernutrition: global and regional exposures and consequences. Lancet 371, 243-260.

4. United Nations (2015) The Millennium Development Goals Report 2015. http://www.un.org/millenniumgoals/2015_MDG_ Report/pdf/MDG\%202015\%20rev\%20\%28July\%201\%29.pdf (accessed October 2015).

5. UNICEF (2013) Improving Child Nutrition: The Achievable Imperative for Global Progress. http://www.unicef.org/gambia/ Improving_Child_Nutrition_-_the_achievable_imperative_for_ global_progress.pdf (accessed October 2015).

6. United Nations Development Programme (2015) Transforming Our World: The 2030 Agenda for Sustainable Development. https://sustainabledevelopment.un.org/content/documents/ $21252030 \% 20$ Agenda\%20for\%20Sustainable\%20Development $\%$ 20web.pdf (accessed March 2016).

7. Milman A, Frongillo EA, de Onis M et al. (2005) Differential improvement among countries in child stunting is associated with long-term development and specific interventions. J Nutr 135, 1415-1422.

8. Marc A, Verjee N \& Mogaka S (2015) The Challenge of Stability and Security in West Africa. http://elibrary. worldbank.org/doi/book/10.1596/978-1-4648-0464-9 (accessed October 2015).

9. Bredenkamp C, Buisman LR \& Van de Poel E (2014) Persistent inequalities in child undernutrition: evidence from 80 countries, from 1990 to today. Int J Epidemiol 43, 1328-1335.

10. Stevens GA, Finucane MM, Paciorek CJ et al. (2012) Trends in mild, moderate, and severe stunting and underweight, and progress towards MDG 1 in 141 developing countries: a systematic analysis of population representative data. Lancet 380, 824-834.

11. Tzioumis E, Kay MC, Bentley ME et al. (2016) Prevalence and trends in the childhood dual burden of malnutrition in low- and middle-income countries, 1990-2012. Public Health Nutr 19, 1375-1388.

12. Aurégan X (2014) Géopolitique de la Chine en Côte d'Ivoire: La puissance chinoise à l'école ivoirienne et africaine. https://tel.archives-ouvertes.fr/tel-01190744/ (accessed October 2015).

13. Vidjannangni A (2011) La complexité de la question identitaire en Côte d'Ivoire. http://www.archipel.uqam.ca/id/ eprint/4180 (accessed October 2015).

14. N'Cho S, Kouassi L, Koffi AK et al. (1995) Enquête Démographique et de Santé, Côte d'Ivoire 1994. http:// dhsprogram.com/publications/publication-FR66-DHS-FinalReports.cfm (accessed November 2014).

15. Institut National de la Statistique/Côte d'Ivoire \& ORC Macro (2001) Enquête Démographique et de Santé, Côte d'Ivoire 1998-1999. http://dhsprogram.com/publications/ publication-FR129-DHS-Final-Reports.cfm (accessed November 2014).

16. Institut National de la Statistique/Côte d'Ivoire \& ICF International (2012) Enquête Démographique et de Santé et à Indicateurs Multiples de Côte d'Ivoire 2011-2012. http://dhsprogram.com/publications/publication-FR272-DHSFinal-Reports.cfm (accessed November 2014).

17. The DHS Program (2014) Demographic and Health Surveys. http://dhsprogram.com/data/available-datasets.cfm (accessed July 2015).
18. Institut National de la Statistique, Comité National du Recensement (1998) Recensement Général de la Population et de l'Habitat - Côte d'Ivoire 1988. Volume 3: analyse des résultats définitifs. Tome 3: caractéristiques socio-économiques de la population. https://www.odsef.fss.ulaval.ca/sites/ odsef.fss.ulaval.ca/files/fonds_gp/c-doc_323_odsef.pdf (accessed August 2015).

19. MEASURE DHS (2001) Demographic and Health Surveys. http://www.measuredhs.com (accessed July 2015).

20. QGIS Development Team (2012) QGIS Geographic Information System. Open Source Geospatial Foundation Project. http://qgis.osgeo.org/en/site/ (accessed February 2015).

21. World Health Organization (2006) WHO Child Growth Standards: Length/Height-for-Age, Weight-for-Age, Weight-forLength, Weight-for-Height and Body Mass Index-for-Age: Methods and Development. Geneva: WHO; available at http:// www.who.int/childgrowth/standards/Technical_report.pdf? ua $=1$

22. Hagos S, Lunde T, Mariam DH et al. (2014) Climate change, crop production and child under nutrition in Ethiopia; a longitudinal panel study. BMC Public Health 14, 884.

23. Rutstein SO \& Staveteig S (2014) Making the Demographic and Health Surveys Wealth Index Comparable. DHS Methodological Reports no. 9. Rockville, MD: ICF International; available at http://dhsprogram.com/pubs/pdf/MR9/ MR9.pdf

24. MEASURE DHS (2012) Sampling and Household Listing Manual: Demographic and Health Surveys Methodology. http://dhsprogram.com/pubs/pdf/DHSM4/DHS6_Sampling Manual_Sept2012_DHSM4.pdf (accessed August 2015).

25. United Nations, Department of Economic and Social Affairs, Population Division (2015) World Population Prospects: the 2015 revision, Data. http://esa.un.org/unpd/wpp/ Download/Standard/Population/ (accessed January 2016).

26. Diggle P \& Ribeiro PJ (2007) Model-Based Geostatistics. New York: Springer.

27. Ribeiro PJ \& Diggle PJ (2001) geoR: a package for geostatistical analysis. R-NEWS 1, 15-18.

28. Cressie N (1988) Spatial prediction and ordinary kriging. Math Geol 20, 405-421.

29. Cressie NAC (1993) Statistics for Spatial Data, Revised Edition. New York: John Wiley \& Sons, Inc.

30. Kulldorff M (1997) A spatial scan statistic. Commun Stat Theory Methods 26, 1481-1496.

31. Kulldorff M \& Nagarwalla N (1995) Spatial disease clusters: detection and inference. Stat Med 14, 799-810.

32. Dahly D, Gordon-Larsen P, Emch M et al. (2013) The spatial distribution of overweight and obesity among a birth cohort of young adult Filipinos (Cebu Philippines, 2005): an application of the Kulldorff spatial scan statistic. Nutr Diabetes 3, e80.

33. Gebreyesus SH, Mariam DH, Woldehanna T et al. (2016) Local spatial clustering of stunting and wasting among children under the age of 5 years: implications for intervention strategies. Public Health Nutr 19, 1417-1427.

34. Dwass M (1957) Modified randomization tests for nonparametric hypothesis. Ann Math Statist 28, 181-187.

35. Haile D, Azage M, Mola $\mathrm{T}$ et al. (2016) Exploring spatial variations and factors associated with childhood stunting in Ethiopia: spatial and multilevel analysis. $B M C$ Pediatr 16, 49.

36. Merlo J (2006) A brief conceptual tutorial of multilevel analysis in social epidemiology: using measures of clustering in multilevel logistic regression to investigate contextual phenomena. J Epidemiol Community Health 60, 290-297.

37. Larsen K \& Merlo J (2005) Appropriate assessment of neighborhood effects on individual health: integrating random and fixed effects in multilevel logistic regression. Am J Epidemiol 161, 81-88. 
38. StataCorp LP (2014) Stata Survey Data Reference Manual, Release 14. College Station, TX: Stata Press; available at http://www.stata.com/manuals14/svy.pdf

39. Adekanmbi VT, Uthman OA \& Mudasiru OM (2013) Exploring variations in childhood stunting in Nigeria using league table, control chart and spatial analysis. BMC Public Health 13, 361.

40. Getis A \& Ord JK (1992) The analysis of spatial association by use of distance statistics. Geogr Anal 24, 189-206.

41. Anselin L (2004) Review of cluster analysis software. Report in Fulfilment of Consultant Agreement \#2003-04-01 with the North Association of Central Cancer Registries, Inc. https://fr.scribd.com/document/98806044/Cluster-Software-Final (accessed September 2015).

42. Sahn DE (1990) Malnutrition in Côte d'Ivoire: Prevalence and Determinants. Washington, DC: World Bank.

43. Courtin F (2007) Les dynamiques de peuplement induites par la crise ivoirienne dans l'espace ivoiro-burkinabè, au regard de la maladie du sommeil (Population movements caused by the Côte d'Ivoire political crisis in the Côte d'Ivoire-Burkina area, in relation to sleeping sickness). PhD Thesis, University of Montpellier III.

44. Minoiu C \& Shemyakina ON (2014) Armed conflict, household victimization, and child health in Côte d'Ivoire. J Dev Econ 108, 237-255.

45. Bundervoet T, Verwimp P \& Akresh R (2009) Health and civil war in rural Burundi. J Hum Resour 44, 536-563.
46. Akresh R, Verwimp P \& Bundervoet T (2011) Civil war, crop failure, and child stunting in Rwanda. Econ Dev Cult Change 59, 777-810.

47. Minoiu C \& Shemyakina ON (2012) Child health and conflict in Côte d'Ivoire. Am Econ Rev 102, 294-299.

48. Cogneau D \& Jedwab R (2012) Commodity price shocks and child outcomes: the 1990 cocoa crisis in Côte d'Ivoire. Econ Dev Cult Change 60, 507-534.

49. Grimm M, Guenard C \& Mesple-Somps S (2002) What has happened to the urban population in Côte d'Ivoire since the 1980s? An analysis of monetary poverty and deprivation over 15 years of household data. World Dev 30, 1073-1095.

50. Martin-Prével Y, Traissac P, Massamba J-P et al. (2000) Deterioration in the nutritional status of young children and their mothers in Brazzaville, Congo, following the 1994 devaluation of the CFA franc. Bull World Health Organ 78, 108-118.

51. Black M, Perez-Escamilla R \& Fernandez Rao S (2015) Integrating nutrition and child development interventions: scientific basis, evidence of impact, and implementation considerations. Adv Nutr 6, 852-859.

52. Kandala N-B, Madungu TP, Emina J-BO et al. (2011) Malnutrition among children under the age of five in the Democratic Republic of Congo (DRC): does geographic location matter? BMC Public Health 11, 261. 